\title{
Inhibition of Pancreatic Lipase and Characterization by Extracts From Fruit Pomaces Cultivars Grown in Brazilian Semiarid
}

\author{
Josileide Gonçalves Borges (Corresponding Author) \\ Biotechnology Post graduate Program (PPGBiotec), Feira de Santana State University, Feira \\ de Santana, Bahia, Brazil; Federal University of San Francisco Valley (UNIVASF). Av José \\ Sá de Maniçoba S/N, Centro, 56304-917, Petrolina, Pernambuco, Brazil \\ E-mail: josileide.borges@univasf.edu.br
}

Jackson Roberto Guedes da Silva Almeida

Biotechnology Post graduate Program (PPGBiotec), Feira de Santana State University, Feira de Santana, Bahia, Brazil; Federal University of San Francisco Valley (UNIVASF). Av José Sá de Maniçoba S/N, Centro, 56304-917, Petrolina, Pernambuco, Brazil

E-mail: Jackson.guedes@univasf.edu.br

Juliana Anielle Ribeiro de Sá

Federal University of San Francisco Valley (UNIVASF). Av José Sá de Maniçoba S/N, Centro, 56304-917, Petrolina, Pernambuco, Brazil. E-mail: july_anielle@hotmail.com

\section{Kaline Stela Pires Bezerra}

Federal University of San Francisco Valley (UNIVASF). Av José Sá de Maniçoba S/N, Centro, 56304-917, Petrolina, Pernambuco, Brazil. E-mail: stela.farma@gmail.com

Patricia Kauanna Fonseca Damasceno

Feira de Santana State University (UEFS). Av. Transnordestina, s/n - Novo Horizonte, 44036-900, Feira de Santana - Bahia, Brazil. E-mail: patriciakauanna@hotmail.com

Isabella Mary Alves Reis 
Feira de Santana State University (UEFS). Av. Transnordestina, s/n - Novo Horizonte, 44036-900, Feira de Santana - Bahia, Brazil. E-mail: Isabella.alvesreis@gmail.com

\title{
Marigilson Pontes de Siqueira Moura
}

Federal University of San Francisco Valley (UNIVASF). Av José Sá de Maniçoba S/N, Centro, 56304-917, Petrolina, Pernambuco, Brazil. E-mail: marigilson.moura@univasf.edu.br

Received: Sep. 8, 2019

doi:10.5296/jas.v7i4.15410
Accepted: Nov. 6, 2019

Published: Nov. 10, 2019

URL: https://doi.org/10.5296/jas.v7i4.15410

\begin{abstract}
Investigate action of pancreatic lipase inhibition and characterization of extracts obtained from fruit pomace cultivars grown in Brazilian semiarid. Phytochemicals of Vitis labrusca, Passiflora edulis flavicarpa Deg., Citrus sinensis L Osbeck, and Punica granatum L. were extracted by maceration in a hydroethanolic solution. Inhibition activity of pancreatic lipase was performed by ELISA reader. To identify which compounds would probably be responsible for inhibitory activity, extracts were characterized by method of total phenolics using folin ciocalteau, phenolic acids and flavonoids were identified by HPLC, antioxidant potential was quantified by DPPH. With exception of pomegranate seed, all other pomace showed potential for inhibition of lipase. However, V. labrusca had higher percentage of inhibition (89.74\%), this percentage similar to that obtained by commercial orlistat inhibitor, which would indicate its use as an efficient inhibitor. For all extracts were found several phytochemical compounds with phenolic characteristics, however, pomaces of $P$. granatum peel and $V$. labrusca showed best results in total phenolic and antioxidant activity. $P$. granatum peel had a high content of total phenolics $\left(82.50 \mathrm{EAG} \mathrm{g}^{-1}\right)$ and the best antioxidant activity $\left(\mathrm{IC}_{50}=1.47 \mu \mathrm{g} \mathrm{mL}^{-1}\right)$. All pomace extracts showed varied secondary metabolites, although antioxidant activity from grape and passion fruit pomaces showed potential for inhibition of lipids absorption.
\end{abstract}

Keywords: pancreatic lipase, total phenolic, antioxidant activity, phenolic acids, flavonoids

\section{Introduction}

In semiarid climate from Brazilian northeast, various fruit cultures have been adapted to intensive production generating large quantities of agroindustrial waste. Food industry produces a lot of waste with high value of (re)use and several studies have shown that this food processing industrial waste is rich in phenolic which can be applied as antioxidant compounds. These phenolic compounds are able to reduce formation of free radicals that cause cell damage generating benefits to health of population in treatment of non-communicable diseases (Antoniolly et al., 2013; Sousa et al., 2014).

Nowadays, both obesity and systemic inflammatory process have leaded development of 
diseases such as: insulin resistance, cardiovascular disease, their complications, type 2 diabetes mellitus, dyslipidemia, gallbladder disease, orthopedic problems, and several types of cancer (Bustanji et al., 2011; Gruzdeva; Boradkina, \& Uchasova, 2018). All these metabolic changes could be minimized with consumption of foods rich in polyphenols, since these bioactive compounds have been known by their anti-inflammatory, antiobesity, and hypoglycemic activities (Ramirez; Dávalos, \& Mora, 2017).

It is worth noting that researches have demonstrated relation between consumption of fruit pomaces and promoting public health. Fruit pomaces from Vitis labrusca were used in medicine due to phytochemicals properties including antioxidants, anti-inflammatory, and antimicrobial activities among others (Bakkali; Averbeck \&, Averbeck, 2008). Passiflora edulis have been used as sedative, diuretic, vermifuge, anti-drug, as well as in treatment of hypertension and menopausal symptoms (Dhawan; Dhawan \&, Sharma, 2004). Sousa et al. (2014) reported that flavonoids from Citrus sinensis exhibit antioxidant, anticarcinogenic, antiviral, anti-inflammatory, and anti-allergic activities and that Punica granatum pomace is popularly used for treating various health problems mainly gastrointestinal and inflammatory. Therefore, the main aim of this study was to characterize fruit pomaces from Brazilian semiarid region assessing antioxidant potential of these pomaces, as well as quantification of total phenolics, phenolic acids and flavonoids, and porcine pancreatic lipase inhibition.

\section{Material and Methods}

\subsection{Materials}

In experimental part, standard analytical reagents were used: gallic acid, calcium chloride, sodium chloride, sodium carbonate, buffer tris- $\mathrm{HCl}$ (Synth), alcohol ethanol, and ascorbic acid (Vetec), Folin-Ciocalteau, butyl hydroxyanisole (BHA), butyl hydroxytoluene (BHT), 2,2-diphenyl-1-pricrilhydrazyl (DPPH ), pancreatic lipase II, methanol, phenolic acid and flavonoid standards, p-nitrophenyl palmitate, Triton-X 100 (Sigma Aldrich).

\subsection{Preparation of Fruit Pomaces}

In nature fruits of Passiflora edulis $f$. flavicarpa, Citrus sinensis, and Punica granatum were obtained from local farmers. Grape waste of Vitis labrusca (20\% violet and 80\% premature Isabel) were kindly supplied from Cooperativa Agrícola Nova Aliança (COANA) from Petrolina city, Brazil. After extracting juice of in nature fruits, solid parts (pomace) were dried separately in a greenhouse with forced circulation of air $\left(40{ }^{\circ} \mathrm{C}\right)$. Dry samples were ground in coffee grinder (Candence), sieved to obtain a uniform size particulate (40 mesh), and stored in plastic bags.

\subsection{Extraction of Total Phenolic Compounds}

In order to prepare the extracts, initially $8.0 \mathrm{~g}$ of pomace were weighted and added in $100 \mathrm{~mL}$ hydroethanolic solution $(1: 3 \mathrm{v} / \mathrm{v})$. This mixture was incubated for $96 \mathrm{~h}$ and stored in dark conditions, i.e. protected from light environment. Determination of total phenolics of extracts was carried out spectrophotometrically using Folin-Ciocalteau reagent (Swain \& Hillis, 1959). Absorbances were measured in spectrophotometer at $740 \mathrm{~nm}$ (New 1600uV Model, New 
Instruments, New York, EUA) using a quartz cells of $10 \mathrm{~mm}$ path length. A linearity of method was determined for gallic acid between 5.0 and $80 \mu \mathrm{g} \mathrm{mL} \mathrm{m}^{-1}$ (O.D. $=16.155$ [gallic acid $\left.\left.\mathrm{mg} \mathrm{mL}^{-1}\right]-0.0041, \mathrm{R}^{2}=0.9969\right)$. Phenol content was expressed as equivalent of gallic acid (GAE) in mg of gallic acid per $g$ fruit extract, which was obtained from application of equation: $\mathrm{GAE}=\mathrm{C} \times \mathrm{V} / \mathrm{m}$;

Where GAE = gallic acid equivalents in $\mathrm{mg} \mathrm{g}^{-1}, \mathrm{C}=$ concentration of gallic acid in $\mathrm{mg}, \mathrm{V}=$ volume of extract used in testing, and $\mathrm{m}=$ mass in $\mathrm{g}$ extract.

\subsection{Analysis of Antioxidant Activity}

Free radical scavenging activity of fruit extracts was determined using DPPH method (Swain $\&$ Hillis, 1959). In brief, stock solutions of extracts $\left(1.0 \mathrm{mg} \mathrm{mL}^{-1}\right)$ were prepared in ethanol. After that, dilutions from these stock solutions were prepared at 1.0, 3.0, 9.0, 27.0, 82.0, and $243.0 \mu \mathrm{g} \mathrm{mL}^{-1}$ using same solvent. One aliquot of $2.5 \mathrm{~mL}$ of dilutions were mixed with 1.0 $\mathrm{mL}$ DPPH. After $30 \mathrm{~min}$, absorbance values were measured at $518 \mathrm{~nm}$ and converted into percentage antioxidant activity (AA) using following equation:

$\mathrm{AA} \%=[($ control absorbance-absorbance of sample $) /$ control absorbance $] \times 100$.

$\mathrm{IC}_{50}$ values were calculated based on final concentration of dry fruit extract required to decrease $50 \%$ of initial concentration. All $\mathrm{IC}_{50}$ values were calculated using Graph Pad Prism 5.0 program. DPPH solution and ethanol were used as negative controls. Ascorbic acid, BHT, and BHA were used as positive controls. All trials were conducted in triplicate.

\subsection{Identification of Phenolic Acid and Flavonoid Compounds by HPLC-DAD}

All extracts were analyzed by high-performance liquid chromatography using a Dionex Ultimate 3000chromatograph with diode Array Detector (HPLC-DAD) from Thermo Fisher Scientific (Orion, USA), and data were analyzed using software Shimadzu ${ }^{\circledR}$ LC solution 1.0 (Japan). All samples were assessed using the following conditions: 18 ACE column (150 x $4.6 \mathrm{~nm})$ as stationary phase mark ACT, a mixture of $0.1 \% \mathrm{H}_{3} \mathrm{PO}_{4}$ and methanol $(1: 10 \mathrm{v} / \mathrm{v})$ was used as analytical and mobile phase, flow of $1 \mathrm{~mL} \mathrm{~min}^{-1}$ mobile phase, $20 \mu \mathrm{L}$ sample injection, and oven maintained at $30{ }^{\circ} \mathrm{C}$. All solutions were filtered and degassed through $0.22 \mu \mathrm{m}$ membrane filters (Millipore, Bedford, USA). Standards were used: quercetin/naringin, caffeic acid, chlorogenic acid, catechin, calicopteria, quercetin/rutin, rutin, hesperidin, and gallic acid. Qualitative analysis was carried out by comparison of retention times (Rt) and UV spectra between extract chromatograms and chromatograms of phenolic and flavonoid patterns.

\subsection{Evaluation of Pancreatic Lipase Inhibition}

Inhibition of lipase absorption in vitro was assessed by testing Pancreatic Lipase inhibition (LP) recommended by Souza et al. (2012). Enzyme pancreatic lipase at $10 \mathrm{~g} \mathrm{~L}^{-1}$ was prepared in buffer Tris-HCl $50 \mathrm{mmol} \mathrm{L}^{-1} \mathrm{pH} 8.0$, and all vegetal extracts and positive control (Orlistat) were prepared at $100 \mu \mathrm{g} \mathrm{mL}^{-1}$. The p-nitrophenyl palmitate (lipase substrate) $8 \mathrm{mmol} \mathrm{L}^{-1}$ was disbanded in Triton-X $1000.5 \%(\mathrm{w} / \mathrm{v})$ at $37{ }^{\circ} \mathrm{C}$. For every analysis, reaction mixture was incubated for $60 \mathrm{~min}$, and in each analysis, extracts were pre-incubated hatching with enzyme 
for $10 \mathrm{~min}$, before addition of substrate and beginning of count of time, read at $405 \mathrm{~nm}$ using an ELISA Micro Well plate reader (BIO-TEK, Synergy HT). Lipase inhibition was obtained from tests in absence of extracts (activity without inhibitor) according to equation \%:

$$
\mathrm{ILP}=100 \%-\left\{\left[\left(\mathrm{Abs}_{\text {control }}\right)\left(\mathrm{Abs}_{\text {teste }}\right) \times 100\right] / \mathrm{Abs}_{\text {control }}\right\}
$$

Where, $A b s_{\text {teste }}$-Absorbance of the sample and $\mathrm{Abs}_{\text {control }}$ Absorbance of the control.

\subsection{Statistical Analysis}

Statistical analysis was performed by One-way ANOVA followed by Tukey's pair wise comparisons using program STATISTICA ${ }^{\circledR} 7.0$, values were considered significant at $\mathrm{p}<$ 0.05 . All determinations were performed in triplicate, data were expressed as average \pm standard deviation. Calculations of $\mathrm{IC}_{50}$ values were calculated by linear regression using Graph Pad Prism 5.0 program.

\section{Results and Discussion}

\subsection{Phenolic Compounds and Antioxidant Activity}

Phenolic compounds are formed in secondary metabolism of plants having functions of defense against attack of pests. Such compounds are mainly related for antioxidant activity in fruit, quality of food, potential benefits to health (Li et al., 2006; Burin et al., 2010; Karling et al., 2017; Grygorieva et al., 2018). Total phenolics were calculated using standard curve of gallic acid (O.D. $=16.155$ [gallic acid $\mathrm{mg} \mathrm{mL}^{-1}$ ] $\left.-0.0041, \mathrm{R}^{2}=0.9969\right)$, which was related for $100 \mathrm{~mL}$, then amount of dry mass, GAE expressed in $\mathrm{mg} / 100 \mathrm{~g}$. Phenolic compounds and antioxidant activity results were expressed as average \pm standard deviation (SDs).

It could be correlated total phenolic content with antioxidant activity measured by DPPH, i.e. pomaces that presented a higher content of total phenolics also had lowest IC50 levels. For analysis of antioxidant activity, lower IC50 greater antioxidant activity measured by DPPH. Pomegranate peel had highest total phenolic content (82.50 mg GAE), lower IC50 (1.47 $\mathrm{g}$ $\mathrm{mL}^{-1}$ ) followed by grape, pomegranate, orange, and passion fruit seeds (Table 1).

Table 1. Total phenolics and antioxidant activity from extract pomaces

\begin{tabular}{ccc}
\hline Groups & $\begin{array}{c}\text { Total phenolics* } \\
\left(\mathbf{m g ~ G A E}^{-1}\right)\end{array}$ & DPPH (IC50)* $^{*}$ \\
\hline Punica granatum (peel) & $82.50 \pm 0.01^{\mathrm{a}}$ & $1.47 \pm 0.02^{\mathrm{a}}$ \\
Punica granatum (seed) & $5.00 \pm 0.58^{\mathrm{e}}$ & $23.34 \pm 0.89^{\mathrm{c}}$ \\
Citrus sinensis & $13.75 \pm 0.01^{\mathrm{c}}$ & $99.81 \pm 2.59^{\mathrm{d}}$ \\
Passiflora edulis & $6.25 \pm 0.01^{\mathrm{d}}$ & $283 \pm 1.46^{\mathrm{e}}$ \\
Vitis labrusca & $32.50 \pm 0.23^{\mathrm{b}}$ & $15.94 \pm 0.58^{\mathrm{b}}$ \\
\hline Default & & \\
\hline Ascorbic acid & - & $1.92 \pm 0.28$ \\
BHA & - & $3.68 \pm 0.16$ \\
\hline
\end{tabular}

*Average \pm standard deviation of triplicate analyses. Values that have same letter, in same column, do not show significant differences $(p<0.05)$ by Tuckey to $95 \%$ confidence. 
Li et al. (2006) compared content of phenolic compounds of pulp and peel from pomegranates and they observed that inside of fruit presented $24.4 \mathrm{mg} \mathrm{GAE}^{-1}$ of phenolic compounds, peel $249.4 \mathrm{mg} \mathrm{GAE}^{-1}$. Soares et al. (2008) analyzing total phenolics of Vitis labrusca peel and Vitis vinifera (Isabel) found values of 219.56 and $1.24 \mathrm{mg} \mathrm{GAE}^{-1}$, respectively, using concentration acetone $75 \%(\mathrm{v} / \mathrm{v})$ as solvent extractor. Values obtained in this study were lower than those found by cited researchers.

Anagnostopoulou et al. (2006) found values between 3 and $105 \mathrm{mg} \mathrm{GAE}{ }^{-1}$ depending on organic solvent to pomaces from Citrus sinensis. Da Silva et al. (2013) analyzing aqueous extracts of passion fruit juice found a total phenolic activity of $8.3 \mathrm{mg} \mathrm{GAE}^{-1}$. Values found in this study were $6.25 \mathrm{mg} \mathrm{GAE}^{-1}$ in experimental conditions, however, high light of this study was pomace rather than fruit juice.

Discrepancy between results found in work can be explained by variations in maturity, variety, cultural practices, geographical origin, growth stage, and fruit harvest conditions (Kim, Jeong, \& Lee, 2003; Bof et al., 2012; Braga et al., 2016). In addition, it could be inferred that all values obtained here might vary depending on influence of parameters mentioned early, besides type and quantity of solvent and method used in extraction. Antioxidant effect reflects cumulative action of all antioxidants present in extract, hence it is considered fundamental parameter to establish health benefits of food products (Viapiana \&, Wesolowski, 2017).

\subsection{Identification of Phenolic Acids and Flavonoids Compounds by HPLC-DAD}

UV spectra of main peaks showed presence of secondary metabolites with phenolic characteristics. Chromatogram of seed and peel P. granatum revealed presence of few compounds, seed showed only three peaks with low retention times characteristic of high polarity compounds with UV spectra of phenolic acids (Figure 1). They showed peaks 1 with UV-DAD spectra characteristic of gallic acid $(\lambda \max 219,270 \mathrm{~nm})$, peaks 2 with spectra characteristic of ellagic acid $(\lambda \max 254,368 \mathrm{~nm})$, peak 3 with spectra of ellagitanins ( $\lambda \max$ $256,374 \mathrm{~nm}$ ) (Figure 2). These compounds have already been described in literature by other authors as belonging to this pomace (Jain et al., 2011; Amyrgialaki et al., 2014; Gullon et al., 2016). 


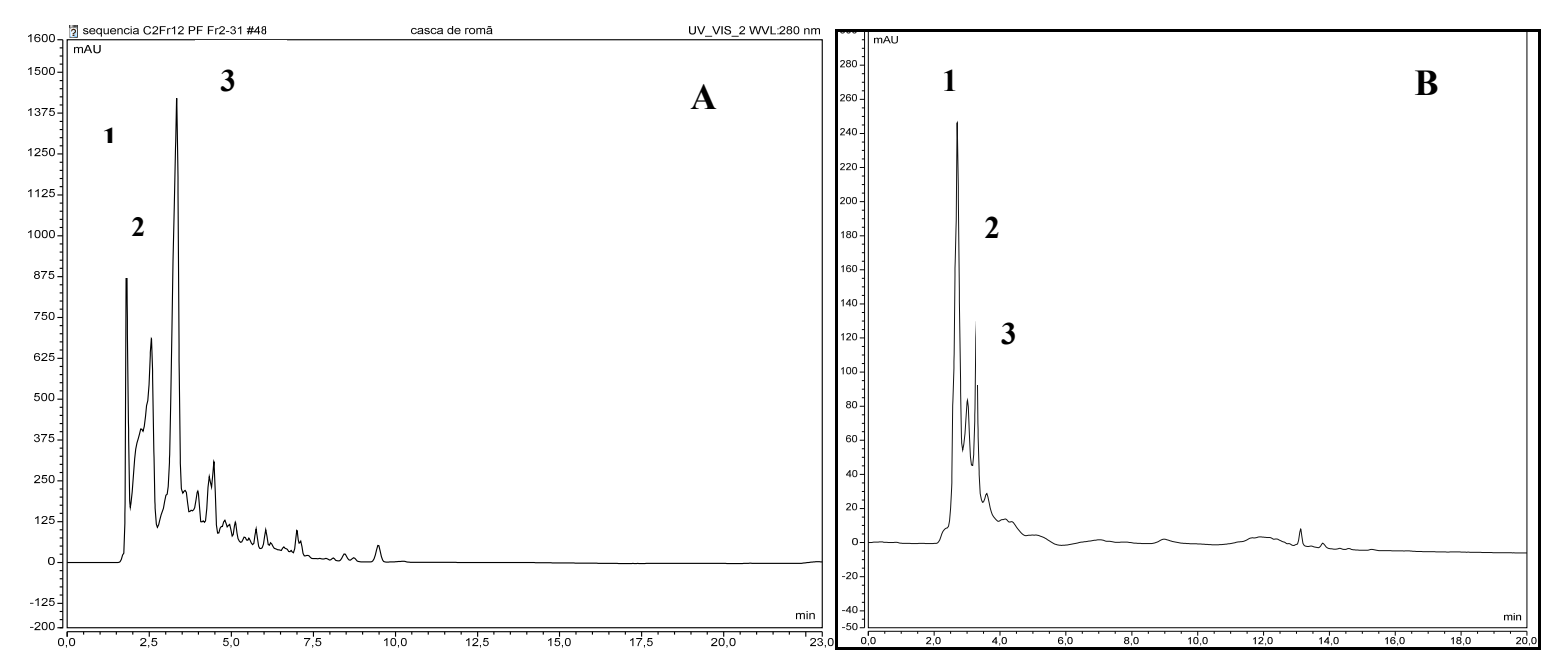

Figure 1. Chromatogram of peel pomace extract (A) and P. granatum seed (B)
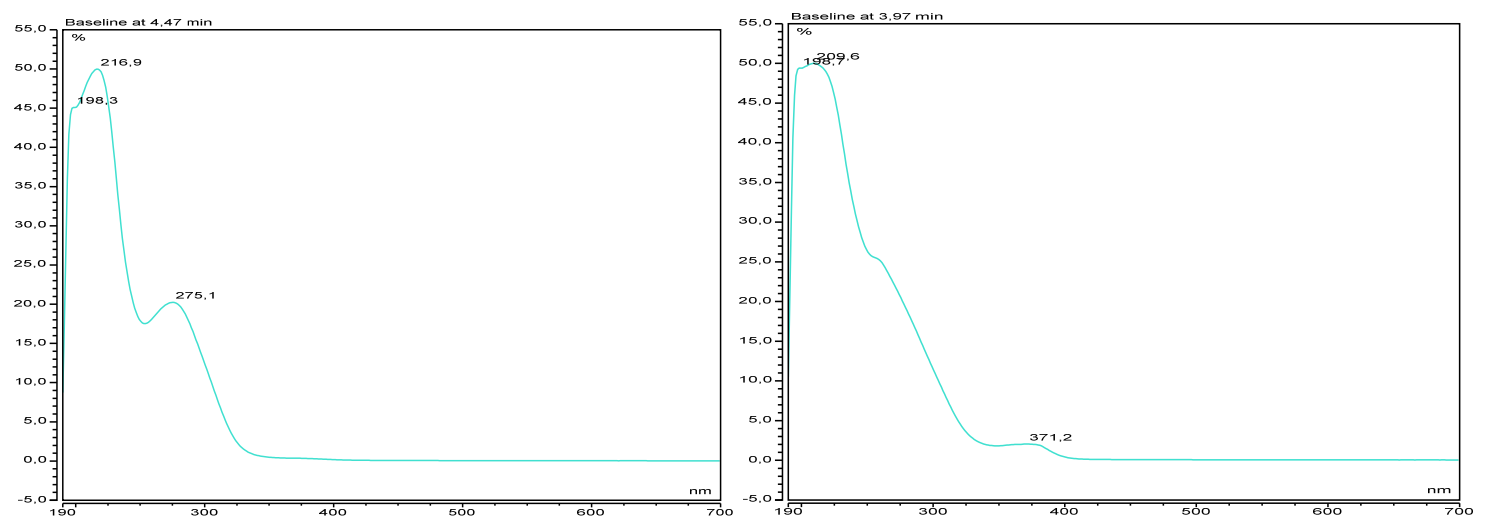

Figure 2. UV-DAD Spectra of peel pomace extract and $P$. granatum seed

Chromatogram of $C$. sinensis (Figure 3) presented various phenolic compounds with UV spectra characteristic of phenolic acids such as gallic acid (peak1), its derivatives ( $\lambda$ max 271 $\mathrm{nm})$, peak 7 with Rt in $9.64 \mathrm{~min}(\lambda \max 284,328 \mathrm{~nm})$ has been identified as hesperidin by comparison with standard, peak with Rt 10.45 min presented $\lambda \max 284,324 \mathrm{~nm}$ suggesting that this is another flavonoid derived from hesperidin (peak 8). C. sinensis presented various phenolic compounds with UV spectra characteristic of phenolic acids too (Figura 4). Hesperetin, its derivatives are flavanones characteristic of sweet orange, mandarin, lemon, while naringenin, their derivatives are characteristic of Vitis vinifera and C. sinensis (Khan, Zill \& Dangles, 2014). 


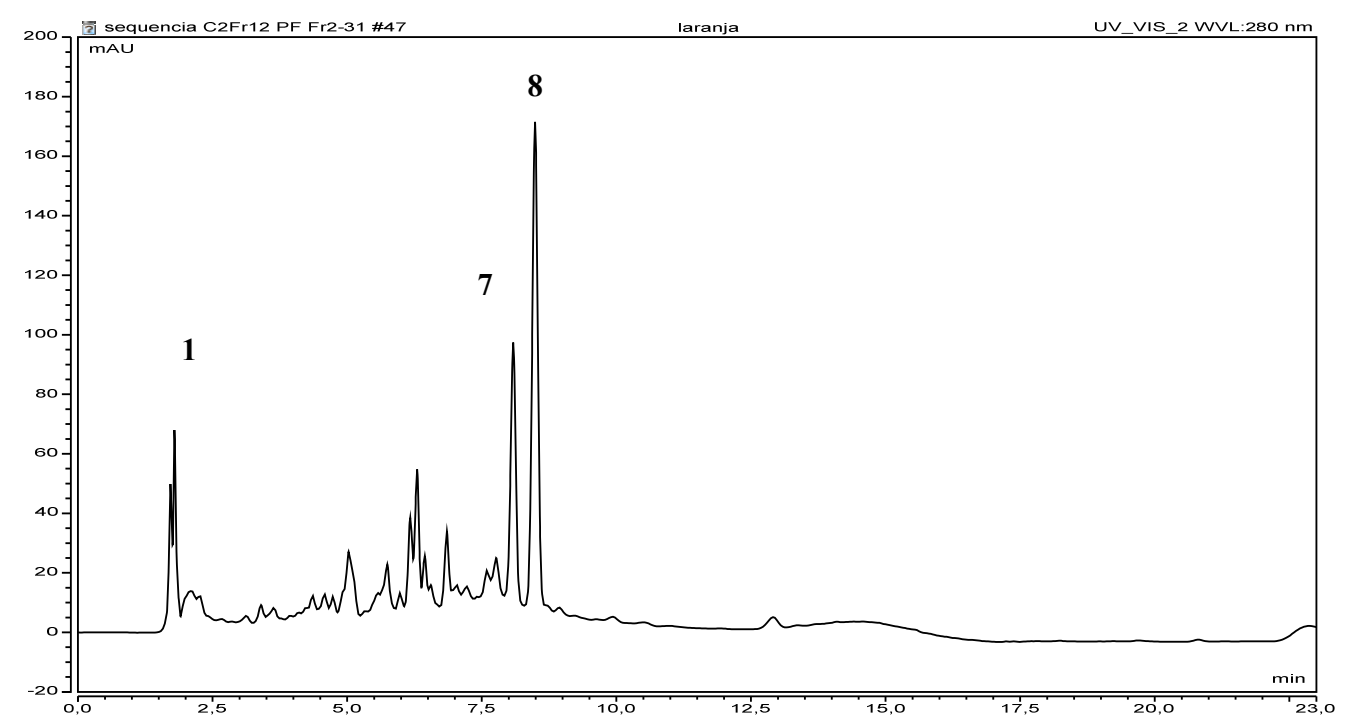

Figure 3. Chromatogram of $C$. sinensis pomace extract

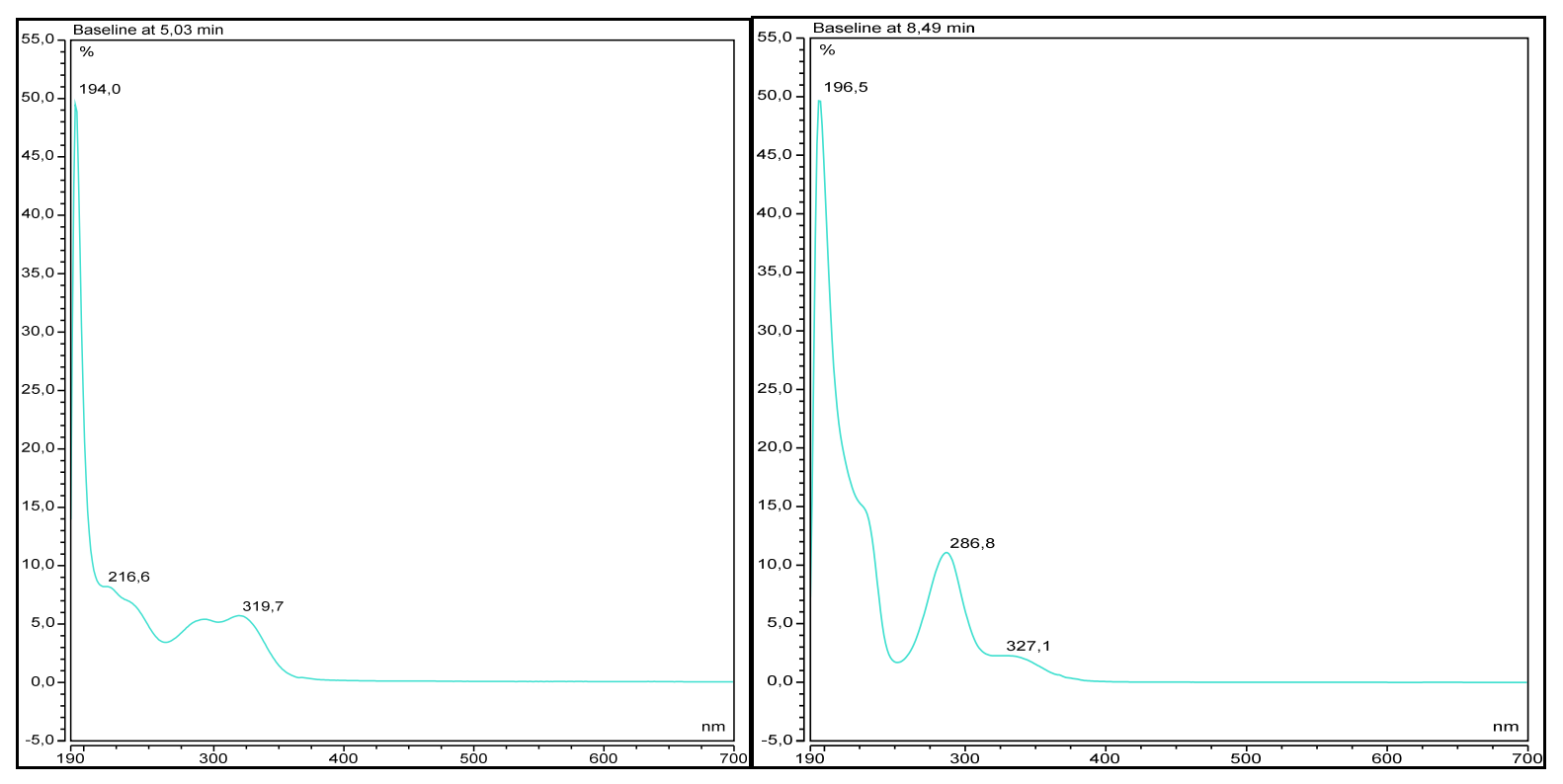

Figure 4. UV-DAD Spectra of $C$. sinensis pomace extract

P. edulis presented three major peaks with UV spectra typical of flavonoids, with two absorption bands between 200 and 400 nm (Figure 5). 

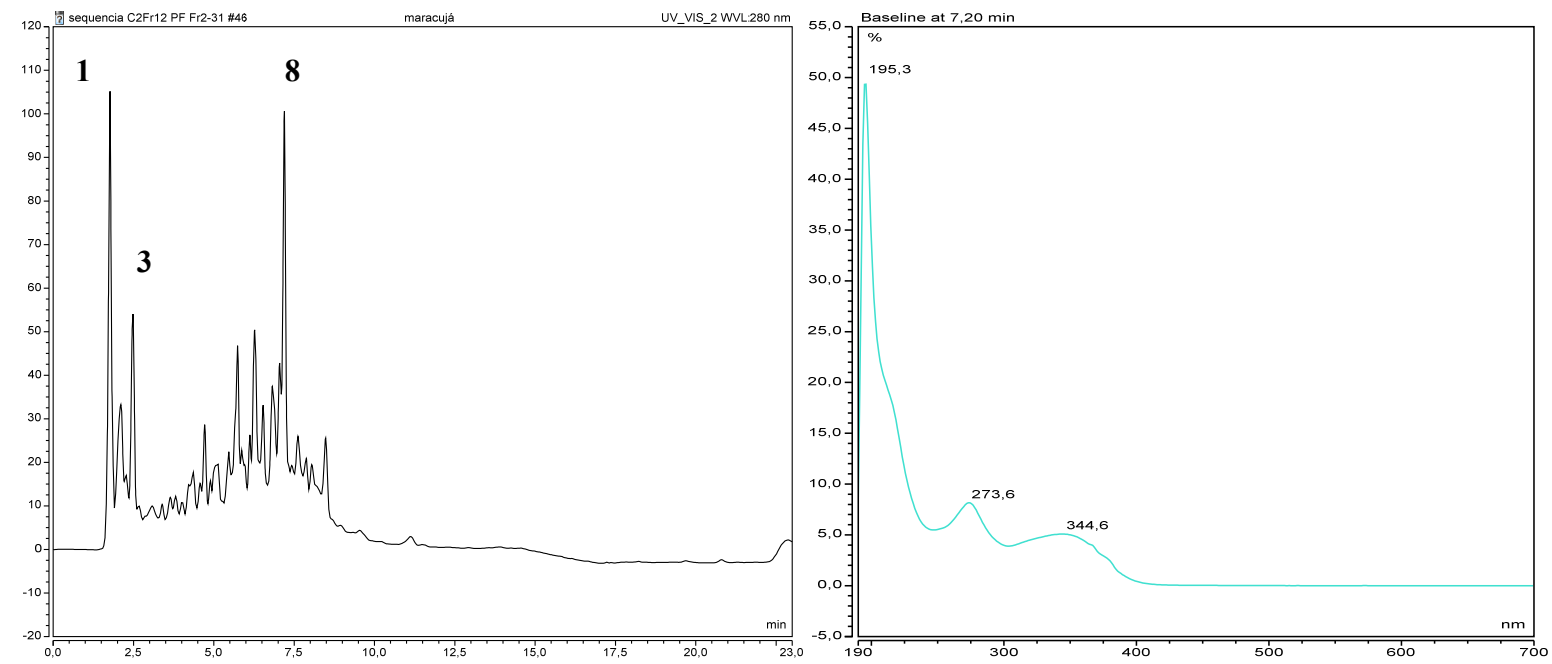

Figure 5. Chromatogram and UV-DAD spectra of Passiflora edulis pomace extract

Peaks at $\operatorname{Tr} 7.03(\lambda \max 270,342 \mathrm{~nm}), 8.19(\lambda \max 269,348 \mathrm{~nm})$ and $9.59(\lambda \max 271$ and 339 $\mathrm{nm}$ ) have comparable UV-DAD spectra to luteoline ( $\lambda \max 270,344 \mathrm{~nm}$ ) suggesting presence of flavonoids derived from this compound. Studies in literature confirm presence of this flavonoid, its derivatives in passion fruit, apigenin, its derivatives were also characterized as belonging to this fruit (Zeraik \& Yariwake, 2010; Ayres et al., 2015).

Bioavailability of polyphenol compounds is an important factor for understanding of their biological activities, health benefits. Gallic acid is most well absorbed in humans in relation to other polyphenols, catechins, followed by flavonones, quercetin glycosides, while prostanglandins, anthocyanidins are poorly absorbed (Rodeiro et al., 2008).

Chromatogram and spectra UV-DAD of extract of $V$. labrusca pomace presented a major peak with ultraviolet spectrum having two absorption bands $(280 \lambda \max , 520 \mathrm{~nm})$ (Figure 6), minority compounds follow same absorption profile; demonstrating presence of compounds with same chromophore groups (anthocyanidins).
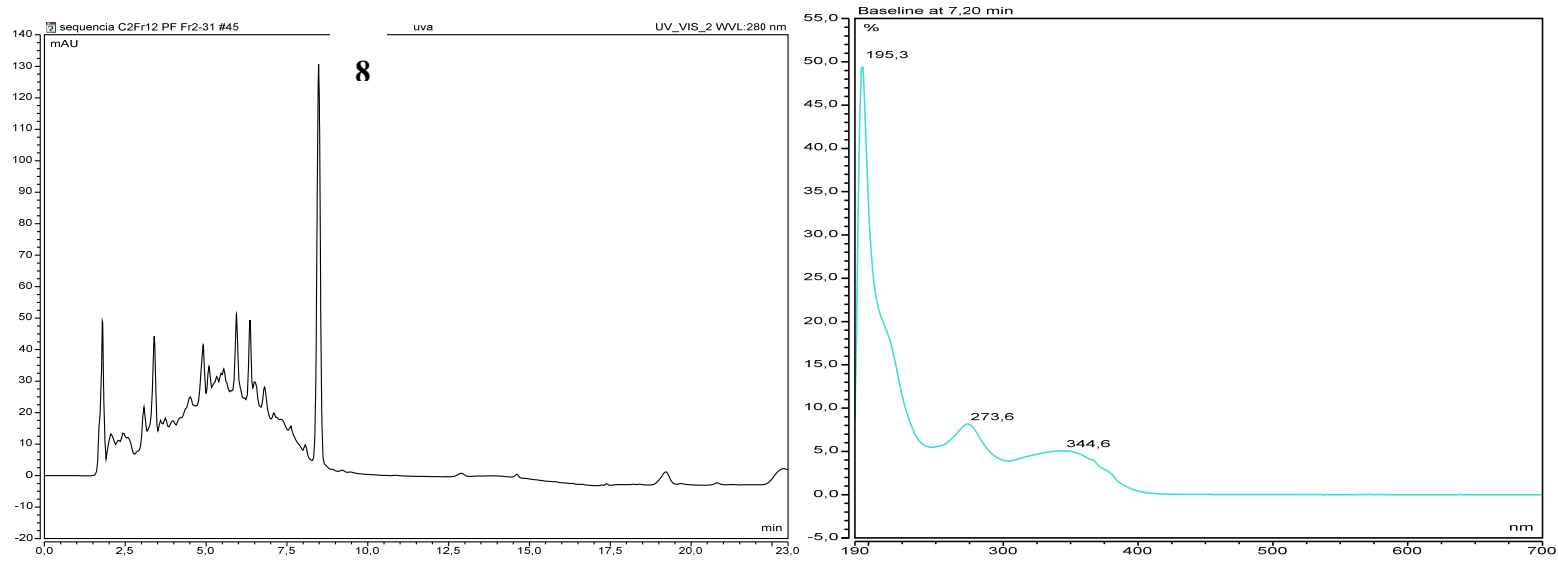

Figure 6. Chromatogram and spectra of grape pomace extract 
Since sugar of anthocyanin is hydrolysed, aglycones (product hydrolysis without sugar) are named anthocyanidins (peak 8), i.e. they have a free structure of sugar residue. There are nineteen naturally occurring anthocyanidins, however, only six normally occur in foods, which are pelargonidin, cyanidin, peonidin, delphinidin, petunidine, malvidin (Schwartz; Von Helbe \&, Giusti, 2010).

\subsection{Evaluation of Pancreatic Lipase Inhibition}

Table 3 depicts results of pancreatic lipase inhibition by fruit pomaces. Extract of $V$. labrusca pomace had a percentage of inhibition of $89.74 \pm 0.07 \%$, similar to that obtained by orlistat which would indicate its use as efficient inhibitor. Analysis of phenolic constituents by HPLC confirmed that this pomace possesses anthocyanidins as main phenolic compounds, which could be considered as main responsible for inhibition of pancreatic lipase.

Table 3. Lipase inhibitor of four fruit pomace

\begin{tabular}{lc}
\hline Inhibitor & \%Inhibition* \\
\hline Punica granatum (peel) & $21.71 \pm 0.31^{\mathrm{e}}$ \\
Punica granatum (seed) & - \\
Citrus sinensis & $29.07 \pm 3.40^{\mathrm{d}}$ \\
Passiflora edulis & $54.15 \pm 1.33^{\mathrm{c}}$ \\
Vitis labrusca & $89.74 \pm 0.07^{\mathrm{b}}$ \\
Orlistat & $93.01 \pm 0.74^{\mathrm{a}}$ \\
\hline
\end{tabular}

*Average \pm standard deviation of triplicate analyses. Values that have the same letter, in same column, do not show significant differences $(p<0.05)$ by Tuckey to $95 \%$ confidence.

Pancreatic lipase is main enzyme for lipids absorption, being responsible for hydrolysis of $50-70 \%$ of total fat in diet (Shi \&, Burn, 2004). Inhibition of pancreatic lipase is a promising way to combat obesity (Maqsood et al., 2017). Some drugs such as orlistat have this purpose, but side effects of this drug have encouraged search for healthier alternatives such as those present in natural plant compounds. Phenolic compounds from fruits, vegetables have been main target of research to find natural substitutes to decrease obesity (Rahim; Takahashi \&, Yamaki, 2015; Ramírez; Dávalos \&, Mora, 2017).

Moreno et al. (2003) evaluated pancreatic lipase inhibition of ethanolics extracts of $V$. vinifera seed. At concentration of $1 \mathrm{mg}$. $\mathrm{mL}^{-1}$, these extracts exhibited greatest inhibitory effect against pancreatic lipase in $30 \%$, although they did not identify which active principle was responsible for inhibition. It can be seen that statements with peel and seed of $V$. labrusca were more efficient in inhibiting lipase than seed of Vitis vinifera and P. edulis also presented 
a high percentage of inhibition indicating its use in obesity treatment. Teixeira et al. (2014) studied inhibitory activity to evaluate extract of leaves of Passiflora nitida kunth in pancreatic lipase by a spectrophotometric assay using orlistat as positive control. Passiflora nitida extract at concentration of $100 \mu \mathrm{g}$. $\mathrm{mL}^{-1}$ showed inhibition of pancreatic lipase of 67.6 $\pm 2.3 \%$ while for orlistat this inhibition was of $74.0 \pm 5.3 \%$.

In spite of peel from $P$. granatum and $C$. sinensis pomaces did not show high levels of lipase inhibition, these peels are cited in literature as beneficial in decreasing LDL cholesterol due to presence of phenolic compounds, fibers. Researchers in their experimental studies in people, animals have shown that both orange juice, hesperidin isolated showed hipolipidemic effect on total cholesterol, LDL cholesterol, triglycerides, increased high-density lipoprotein cholesterol (César et al., 2010; Aptekmann \&, Cesar, 2010).

\section{Conclusions}

Pomaces have potential for nutraceutical development due to their phenolic compounds, and they could be used as adjuvant therapy applied to obesity treatment. Pomegranate peel showed high total phenolic content and excellent antioxidant activity. Chromatograms showed presence of phenolic compounds such as gallic acid, ellagic acid, and elangitanines. Grape and passion fruit extracts showed the best potential for pancreatic lipase inhibition, consequently lower lipid absorption. Grape chromatograms showed that anthocyanidin was the main compound found in this extract, which could be primarily responsible for enzymatic inhibition. Therefore, this study demonstrates the potential of extracts from pomaces as natural inhibitors of lipids absorption.

\section{References}

Amyrgialaki, E., Makris, D. P., Mauromoustakos, A., \& Kefalas, P. (2014). Optimization of the extraction of pomegranate (Punica granatum) husk phenolics using water/ethanol solvent systems and response surface methodology. Industrial Crops \& Products, 59, 216-222. https://doi.org/10.1016/j.indcrop.2014.05.011

Anagnostopoulou, M. A., Kefala, P., Papagerogiou, V. P et al. (2006). Radical scvenging activity of various extracts and fractions of sweet orange peel (Citrus sinensis). Food Chemistry, 94, 19-25. https://doi.org/10.1016/j.foodchem.2004.09.047

Antoniolli, A., Fontana, A.R., Piccoli, P., \& Bottini, R. (2015). Characterization of polyphenols and evaluation of antioxidant capacity in grape pomace of the cv. Malbec. Food Chemistry, 178, 172-178. https://doi.org/10.1016/j.foodchem.2015.01.082

Aptekmann, N. P., \& Cesar, T. B. (2010). Orange juice improved lipid profile and blood lactate of overweight middle-aged women subjected to aerobic training. Maturitas, 67(4), 343-347. https://doi.org/10.1016/j.maturitas.2010.07.009

Ayres, A. S. F. S. J., Araújo, L. L. S., Soares, T. C et al. (2015). Comparative central effects of the aqueous leaf extract of two populations of Passiflora edulis. Brazilian Journal Pharmacology, 25(5), 499-505. https://doi.org/10.1016/j.bjp.2015.06.007 
Bakkali et al. (2008). Biological effects of essential oils- A review. Food Chemistry Toxicology, 46, 446-475. https://doi.org/10.1016/j.fct.2007.09.106

Bof, C. M. J., Fontana, R .C., Piemolini-Barreto, L. T., \& Sandri, I. G. (2012). Effect of freezing and processing technologies on the antioxidant capacity of fruit pulp and jelly. Brazilian Archives of Biology and Technology, 55(1), 107-114.

https://doi.org/10.1590/S1516-89132012000100014

Braga, G. C., Melo, P. S., Bergamaschi, K. B et al. (2016). Extraction yield, antioxidant activity and phenolics from grape, mango and peanut agro-industrial by-products. Rural Sciences, 46(8), 1948-1504. https://doi.org/10.1590/0103-8478cr20150531

Burin,V. M., Falcão, L. D., Gonzaga, L.V et al. (2010). Colour, phenolic content and antioxidant activity of grape juice. Food Sciences \& Technology, 30(4), 1027-1032. https://doi.org/10.1590/S0101-20612010000400030

Bustanji et al. (2011). Screening of some medicinal plants for their pancreatic lipase inhibitory potential. Journal Pharmacology Sciences, 4(2), 81-88. Not doi

César et al. (2010). Cholesterol-lowering effect of orange juice in normolipidemic subjects. Journal of Nutritional, 23(5), 779-789. https://doi.org/10.1590/S1415-52732010000500008

Da Silva, J. K., Cazarin, C. B. B., Colomeu, T. C et al. (2013). Antioxidant activity of aqueous extract of passion fruit (Passiflora edulis) leaves: in vitro and in vivo study. Food Research International, 53(2), 882-890. https://doi.org/10.1016/j.foodres.2012.12.043

Dhawan, K., Dhawan, S., \& Sharma, A. (2004). Passiflora: a review update. Journal of Ethnopharmacology, 94, 1-23. https://doi.org/10.1016/j.jep.2004.02.023

Gruzdevaet al. (2018). Localization of fat depots and cardiovascular risk. Lipids Health Diseases, 17, 218. https://doi.org/10.1186/s12944-018-0856-8

Grygorieva, O., Kucharska, A. Z., Piórecki, N., Klymenko, S., Vergun, O., \& Brindza, J. (2018). Antioxidant activities and phenolic compounds in fruits of various genotypes of American persimmon (Diospyros virginiana L.). Acta Scientiarum Polonorum, Technologia Alimentaria, 17(2), 117-124. https://doi.org/10.17306/J.AFS.0544

Gullon, B., Pintado, M. E., Pérez-Álvarez, J. A et al. (2016). Assessment of polyphenolic profile and antibacterial activity of pomegranate peel (Punica granatum) flour obtained from $\begin{array}{lllll}\text { co-product of juice extraction. Food Control, 59, 94-98. } & \text {. }\end{array}$ https://doi.org/10.1016/j.foodcont.2015.05.025

Jain, V., Murugananthan, G., Deepak, M et al. (2011). Isolation and standardization of various phytochemical constituents from methanolic extracts of fruit rinds of Punica granatum. Chinese Journal of Natural Medicines, 9(6), 0414-0420.

https://doi.org/10.3724/SP.J.1009.2011.00414

Karling, M., Bicas, T. C., Lima, V. A., \& Oldoni, T. L. C. (2017). Grape and Apple Pomaces from Southern Brazil: Valorization of By-Products through Investigation of their Antioxidant 
Potential. Journal Brazilian Chemistry Society, 28(10).

https://doi.org/10.21577/0103-5053.20170014

Khan, M. K., Zill, E. H., \& Dangles, O. (2014). A comprehensive review on flavanones, the major Citrus polyphenols. Journal Food Composition Analysis, 33, 85-104. https://doi.org/10.1016/j.jfca.2013.11.004

Kim, D. O., Jeong, S. W., \& Lee, C. Y. (2003). Antioxidant capacity of phenolic phytochemicals from various cultivars of plums. Food Chemistry, 81(3), 321-326. https://doi.org/10.1016/S0308-8146(02)00423-5

Li,Y., Guo, C., Yang, J et al. (2006). Evaluation of antioxidant properties of pomegranate peel extract in comparison with pomegranate pulp extract. Food Chemistry, 96, 254-260. https://doi.org/10.1016/j.foodchem.2005.02.033

Maqsood, M., Ahmed, D., Atique, I., \& Malik, W. (2017). Lipase inhibitory activity of Lagenaria siceraria fruit as a strategy to treat obesity. Asian Pacific Journal of Tropical Medicine, 10(3), 305-310. https://doi.org/10.1016/j.apjtm.2017.03.010.

Moreno, D. A., Ilic, N., Poulev, A., Brasaemle, D. L., Fried, S. K., \& Raskin, I. (2003). Inhibitory effects of grape seed extract on lipases. Nutritional Journal, 19(10), 876-879. https://doi.org/10.1016/S0899-9007(03)00167-9

Rahim, A. T. M. A., Takahashi, Y., \& Yamaki, K. (2015). Mode of pancreatic lipase inhibition activity in vitro by some flavonoids and non-flavonoid polyphenols. Food Research International, 75, 289-294. https://doi.org/10.1016/j.foodres.2015.05.017

Ramírez et al. (2017). Effect of Ocimum sanctum and Crataegus pubescens aqueous extracts on obesity, inflammation, and glucose metabolism. Journal Functional Foods, 35, 24-31. https://doi.org/10.1016/j.jff.2017.05.028

Rodeiro, I., Donato, M. T., \& Martínez, I et al. (2008). Potential hepato protective effects of new Cuban natural products in rat hepatocytes culture. Toxicology in vitro, 22(5), 1242-1249. https://doi.org/10.1016/j.tiv.2008.04.006.

Schwartz, S. J., Von Helbe, J., \& Giusti, M. M. (2010). Corantes. In: Food chemistry Fennema. 4a ed. Artimed, Porto Alegre: Artmed Publisher.

Shi, Y., \& Burn, P. (2004). Lipid metabolic enzymes: emerging drug targets for the treatment of obesity. Nature Reviews Drug Discovery, 3(8), 695-710.

https://dx.doi.org/10.1038/nrd1469 
Soares, M., Welter, L., Gonzaga, L et al. (2008). Evaluation of antioxidant activity and identification of phenolic acids present in the pomace of Gala variety apples. Food Sciences Technology, 28(3), 727-732. https://doi.org/10.1590/S0101-20612008000300032

Sousa et al. (2014). Chemical composition and bioactive compounds of grape pomace (Vitis viniferaL.), Benitaka variety, grown in the semiarid region of northeast Brazil. Food Sciences and Technology, 34(1), 135-142. https://doi.org/10.1590/S0101-20612014000100020

Souza, S. P., Pereira, L. L. S., Souza, A. A., \& Santos, C. D. (2012). Selection of crude extracts from plants with antiobesity activity. Revista Brasileira de plantas medicinais, 14(4), 643-648. https://doi.org/10.1590/S1516-05722012000400011

Swain, T., \& Hillis, W. E. (1959). Phenolic constituents of Prunus domesticai quantitative analysis of phenolic constituents. Journal Sciences Food Agriculture, 10, 63-66. https://doi.org/10.1002/jsfa.2740100110

Teixeira, L. S., Lima, A. S., Boleti, A. P et al. (2014). Effects of Passiflora nitida kunth leaf extract on digestive enzymes and high caloric diet in rats. Journal of Natural Medicine, 68(2), 316-325. https://doi.org/10.1007/s11418-013-0800-1

Viapiana, A., \& Wesolowski, M. (2017).The Phenolic Contents and Antioxidant Activities of Infusions of Sambucus nigra L. Plant Foods for Human Nutrition, 72(1), 82-87. https://doi.org/10.1007/s11130-016-0594-x

Zeraik, M. L., \& Yariwak, J. H. (2010). Quantification of isoorientin and total flavonoids in Passiflora edulis fruit pulp by HPLC-UV/DAD. Microchemical Journal, 96(1), 86-91. https://doi.org/10.1016/j.microc.2010.02.003

\section{Copyright Disclaimer}

Copyright for this article is retained by the author(s), with first publication rights granted to the journal.

This is an open-access article distributed under the terms and conditions of the Creative Commons Attribution license (http://creativecommons.org/licenses/by/4.0/). 